\title{
A revitalização do Mercosul no contexto da diplomacia de Lula para a América do Sul
}

\author{
Raquel Paz dos Santos \\ Universidade de Santo Amaro, São Paulo, Brasil. \\ Email: raquelpazdossantos@terra.com.br
}

\begin{abstract}
Resumo: O presente estudo analisa as políticas do primeiro governo de Luiz Inácio Lula da Silva, entre 2003 e 2007, voltadas para a revitalização do Mercosul. Neste contexto, sua política externa enfatiza as relações políticas, econômicas e culturais com os países da América do Sul e expressa uma crítica aos Estados Unidos tanto no rechaço das políticas neoliberais quanto da proposta de integração continental através da ALCA, em consonância com o posicionamento da Argentina, Venezuela, Bolívia e de outros governos da "nova esquerda” estabelecidos na região. Este novo paradigma das relações com os vizinhos, impulsionou importantes iniciativas governamentais direcionadas para promover o desenvolvimento regional através de projetos de infraestrutura, energia, segurança e defesa, institucionalização do bloco visando a criação da supranacionalidade e do aprofundamento das relações entre as diversas nações.
\end{abstract}

Palavras-chave: Lula, Mercosul, nova esquerda, cooperação.

\section{La revitalización del Mercosur en el contexto de la diplomacia de Lula para América del Sur ${ }^{1}$}

Resumen: Este estudio analiza las políticas del primer gobierno de Luiz Inácio Lula da Silva, entre 2003 y 2007, volcadas para la revitalización del Mercosur. En este contexto, la política exterior enfatiza las relaciones políticas, económicas y culturales con los países de América del Sur y expresa una crítica a los Estados Unidos, tanto en el rechazo a las políticas neoliberales como en la propuesta de integración continental a través del ALCA, en línea con el posicionamiento de Argentina, Venezuela, Bolivia y otros gobiernos de la "nueva izquierda” establecidos en la región. Este nuevo paradigma de las relaciones con los vecinos, estimuló importantes iniciativas gubernamentales destinadas a promover el desarrollo regional a través de proyectos de infraestructura, energía, seguridad y defensa, la institucionalización del bloque dirigido a la creación de relaciones supranacionales y del fortalecimiento entre las naciones.

Palabras clave: Lula, Mercosur, Nueva Izquierda, cooperación.

\section{The revitalization of Mercosur in the context of Lula's diplomacy towards South America}

Abstract: This study analyzes the politics of the first government of Luiz Inácio Lula da Silva, from 2003 to 2007, focused on the revitalization of Mercosur. 
In this context, foreign policy emphasizes the political, economic and cultural relations with the countries of South America and expresses a criticism to the United States, both in the rejection to neoliberal policies as to the proposed continental integration through the FTAA, in line with the positioning of Argentina, Venezuela, Bolivia and other governments of the "new left" established in the region. This new paradigm of the relationship with neighbors, spurred major government initiatives aimed to promote regional development through infrastructure projects, energy, security and defense, the institutionalization of the block towards the creation of supranational relations and the strengthening of this nations.

Key words: Lula, Mercosur, New Left, cooperation.

$* * *$

\section{Introdução}

Durante o primeiro governo de Luís Inácio Lula da Silva, entre 2003 a 2007, buscou-se construir um novo modelo desenvolvimentista distinto do regionalismo aberto ${ }^{2}$, baseado na concepção de um crescimento sustentável pautado em projetos de industrialização, estímulo ao comércio inter-regional, na implementação de programas voltados para as questões de infraestrutura e energética, defesa e segurança regional e a institucionalização do Mercosul. Como estratégia de política externa, procurou-se incentivar a cooperação na América do Sul, consubstanciando a ideia de que as diretrizes da nova fase de aproximação deveriam se pautar na superação das divergências internas e na ampliação da complementaridade entre as economias.

Dessa forma, este artigo objetiva analisar a nova concepção de desenvolvimento na região a partir da primeira presidência de Lula e as políticas voltadas para a intensificação do processo de integração regional como alternativa as restrições impostas pelos grandes centros capitalistas, sobretudo, os Estados Unidos.

\section{As diferentes concepções do "neodesenvolvimentismo" para a América do Sul}

As análises recentes sobre a conjuntura política da América Latina enfatizam a "virada à esquerda" dos governos da região a partir do início do século XXI. Tal fato se justificaria pelas sucessivas eleições de Hugo Chávez na Venezuela desde 1998, a vitória no Brasil de Lula em 2002, a ascensão de Kirchner a Casa Rosada em 2003, o êxito eleitoral no Uruguai da Frente Amplia representada por Tabaré Vasquez em 2004, o início da presidência de Evo Morales na Bolívia em 2005. Em continuação, no ano seguinte, temos os triunfos de Rafael Correa no Equador e de Daniel Ortega na Nicarágua, assistimos ainda a disputa acirrada no Peru e a evidente fraude eleitoral no México. Todos esses acontecimentos representaram uma transformação de grande importância para o quadro político latino-americano. 
Dentro deste contexto, muitos analistas políticos têm destacado que outra característica comum desses governos institucionalmente eleitos é a instauração de um programa de desenvolvimento capitalista nacional como estratégia de ação. Nesse sentido, parece que há um crescente retorno aos ideais desenvolvimentistas que se proliferaram na região durante as décadas de 1950, 1960 e 1970. Dessa forma, passada a era neoliberal, que gerou forte contestação popular, atualmente, vem se configurando o que podemos denominar como "novo-desenvolvimentismo".

No âmbito sul-americano, José Luís Fiori (2007:1-5) ressalta que essa "nova esquerda" dividiu-se e apresentou diversidades de caminhos para encontrar soluções para os graves problemas enfrentados por seus países. No Chile, no governo de Michelle Bachelet, o projeto "socioliberal" vem gradativamente modificando o modelo econômico ortodoxo das últimas décadas, privilegiando as políticas de universalização e mantendo a qualidade dos serviços públicos de saúde e educação. Ao passo que o projeto "new deal keynesiano" do governo argentino, depois da moratória, redefiniu suas relações com a comunidade financeira internacional e estabeleceu como prioridade absoluta à geração de empregos e a recuperação da massa salarial da população através da utilização da fórmula clássica socialdemocrata europeia em torno da "concertação social” visando conter a inflação. Além da volta da proteção da indústria, estatização de vários serviços públicos e da criação de um programa de reestatização opcional da própria previdência.

Outra proposta de desenvolvimento é definida pelo projeto de "socialismo do século XXI” pronunciado pelo presidente Hugo Chávez e apoiados pelos presidentes da Bolívia e do Equador. Fiori explica que o mesmo inspira-se nas ideias e políticas originárias da Revolução Mexicana que fizeram parte dos programas de diversos governos revolucionários ou nacionalistas da América Latina, tendo como ponto culminante à experiência de "transição democrática ao socialismo" do governo de Salvador Allende, em princípios da década de 1970. Segundo o autor: "Em todos os casos o ponto central foi o mesmo: a criação de um núcleo produtivo estatal, com capacidade estratégica de liderar o desenvolvimento do país, na perspectiva da construção de uma sociedade igualitária. Uma espécie de "capitalismo de Estado" onde convivam o grande capital estatal e privado com as pequenas cooperativas da economia indígena, dentro de um sistema comunal de participação democrática.” (Fiori, 2007:1)

Por último, aponta o "desenvolvimentismo como inclusão social” do segundo mandato de Lula. Seu objetivo estratégico não visaria à construção do socialismo, mas “destravar o capitalismo", na expressão de Fiori, no Brasil para que atinja altas taxas de crescimento, gerando a criação de empregos e aumentos salariais de maneira sustentável, propiciando um fortalecimento da capacidade fiscal de investimento e proteção social do Estado.

Dessa forma, o governo Lula estaria recuperando o projeto desenvolvimentista que remonta aos anos 30 e que apenas sofreu interrupção 
durante a década de 1990. Entretanto, paralelamente, buscaria criar uma vontade política por meio de uma ampla coalizão social e econômica que englobaria as diversas vertentes conservadoras e progressistas do desenvolvimentismo brasileiro que se mantiveram distanciadas ao longo do regime militar.

Outra característica fundamental desse processo em curso é o "regional-desenvolvimentismo" que na concepção do embaixador José Botafogo Gonçalves e do sociólogo Hélio Jaguaribe deveria substituir o modelo "nacional-desenvolvimentismo", pois na sua concepção deve levar-se em conta o conjunto da América do Sul e, em particular, o relacionamento entre Brasil e Argentina, concebido como o núcleo central dessa integração.

Botafogo Gonçalves (2004:1) estabelece quatro pilares para o novo paradigma. Primeiro, a recuperação da importância do Estado como agente planificador a nível regional, além de uma definição mais clara de seu papel como regulador. Segundo, substituição do tradicional conceito de "política industrial” por “política pública de agregação de valor”, tanto na indústria quanto na economia, procurando também eliminar a dicotomia entre mercado externo e interno. Terceiro, a canalização dos recursos estatais para a área dos "serviços públicos naturais" - educação, saúde, infraestrutura, ciência, etc. -, e incentivo à internacionalização das empresas sul-americanas. E por último, a melhoria do quadro de segurança jurídica institucional para atrair investimentos de longo prazo e política regional de promoção das exportações. Na visão do embaixador, que também foi ministro do Desenvolvimento, Indústria e Comercio Exterior, esse paradigma é um projeto em construção.

As reflexões de Hélio Jaguaribe (2005:5) também caminham no mesmo sentido. Ao analisar de modo apreensivo o reduzido o crescimento econômico do Brasil nas últimas décadas, em contraste com o desenvolvimento acelerado durante anos 50, 60 e 70, faz uma convocação à nova geração, na faixa dos 30 anos, a engajar-se na formulação de um novo projeto para o país. Recordando assim, a sua própria experiência no Instituto de Estudos Brasileiros (ISEB), Jaguaribe enfatiza a necessidade de "intelectuais orgânicos", que empenhem sua competência acadêmica a serviço do objetivo público da retomada do desenvolvimento. Todavia, ressalta que as condições do início do século XXI são bem distintas daquelas que foram predominantes no auge do modelo anterior.

Diante desses diferentes projetos, os governos do Brasil e da Argentina buscaram criar uma alternativa de conciliação para viabilizar uma integração regional. Sem dúvida, esse foi o maior desafio de sua liderança, sobretudo a brasileira como maior economia ${ }^{3}$ para buscar a efetivação do Mercosul. Analisaremos a partir de agora alguns dos principais pressupostos pelos quais pautaram a proposta de um novo paradigma desenvolvimentista para a América do Sul. Contudo, ainda hoje permanece a discussão em torno de qual seria o modelo mais apropriado para o desenvolvimento re- 
gional, um debate que transcendeu as chancelarias desses países e está em efervescência entre a intelectualidade, o empresariado, os políticos, os sindicatos, os ambientalistas, entre outros setores da sociedade.

Amado Luís Cervo (2004:2) traz uma relevante contribuição para esse debate ao analisar a política exterior de Lula, ressaltando que houve uma mudança de paradigma em relação ao governo de Fernando Henrique Cardoso. Este último teria se orientado dentro da concepção do que define como Estado normal, no qual o país submetia-se às coerções do centro hegemônico do capitalismo, gerando um efeito "destrutivo" ao enfraquecer a economia nacional e "regressivo" ao reservar para a nação as funções da “infância social”.

De forma oposta, o governo petista assume uma posição que denomina Estado logístico, na qual busca sanar os males da globalização assimétrica através do reforço do núcleo central da economia nacional, reconvertendo a política de comércio exterior em instrumento estratégico de desenvolvimento e da renda líquida do país. Outra característica importante é promover a internacionalização da economia nacional, desde a plataforma regional. Tal posicionamento foi amplamente apoiado pela Argentina, pois segundo Cervo: “A Argentina de Nestor Kirchner e Roberto Lavagna reassumiu, no governo Lula, a condição de parceiro político número um. Ambos os países concertam posições comuns na OMC, ALCA, negociações com a União Europeia, G-20 e América do Sul. Ambos reforçam o Mercosul com o fim de elevar a capacidade de negociação e de obter resultados sobre cenário internacional.” (Cervo, 2004:5)

Numa análise comparativa com a política externa brasileira, o governo Kirchner também representou uma guinada na posição da Argentina frente aos países centrais, especialmente os EUA, buscando um desenvolvimento mais autônomo e priorizando a América do Sul em sua agenda presidencial.

Nesse sentido, o conceito de Estado Logístico pressupõe a superação tanto do modelo de inserção liberal quando o nacionalismo desenvolvimentista do passado. Na concepção desse novo paradigma, o repasse de responsabilidade do Estado empresário caberia mais à sociedade. Porém, isso não significaria o fim do empreendimento estatal, este ocorreria quando apresentasse capacidade de construção de uma competitividade sistêmica global. Assim, a formulação logística em execução teria dois componentes: primeiro, advogar-se-ia a construir os meios de poder e, em segundo, seu uso para proporcionar vantagens comparativas de natureza intangível, como a ciência, a tecnologia e a capacidade empresarial.

De acordo com Dominique Meunier (2008:152), a mudança na política exterior argentina observou-se com o abandono progressivo da perspectiva de alinhamento estratégico com os Estados Unidos, priorizada durante os anos 1990, uma vez que a crise de 2001 inscreveu-se no contexto do fracasso do neoliberalismo. Assim, desde o início de seu mandato, em 2003, Kirchner reconheceu a necessidade de cercar-se de novos aliados 
para melhorar a posição de seu país no cenário mundial. Isso pode explicar a sua decisão em dar centralidade à integração regional para reforçar seu poder de negociação perante os países desenvolvidos em temas importantes como a dívida externa, a luta contra a pobreza e a exclusão social.

Dessa forma, mesmo que o rechaço da ideologia neoliberal seja uma forte característica em comum aos dois governos, a catástrofe econômica argentina foi um traço peculiar, mas no conjunto contribuiu para incentivar a aproximação. Pelos motivos apontados anteriormente, não interessava a Lula o declínio da segunda maior economia sul-americana, por isso, procurou apoiar o seu vizinho diante da indiferença dos EUA e do FMI.

Esses fatores são relevantes para compreendermos porque as relações entre os dois governos representaram um reforço, um significativo impulso para o projeto do Mercosul. Como destaca Bernal-Mesa: “Com Kirchner lá Argentina se acerco más al Brasil em lá Vision sobre ele regionalismo al qual se aspirava: entre lá proposta norte-americana de ALCA y lá interaciona plena desenhada com ele MERCOSUR, ambos os países optaram decididamente por lá opcional euramericana”. (2008: 164-165)

\section{América do Sul como um dos eixos centrais da diplomacia do governo Lula}

Desde o início de seu governo em 2003, a política externa de Lula tem gerando diversas discussões sobre a influência da ideologia do Partido dos Trabalhadores (PT) em sua agenda. Neste sentido, a ênfase nas relações Sul-Sul, a forte relação com os governos de esquerda sul-americanos, o discurso contundente sobre a relevância do papel de liderança brasileira no cenário regional e mundial e, ainda, a defesa da necessidade de redução das desigualdades sociais no mundo tem sido interpretadas como uma de ideologização da política exterior. Entretanto, diversos setores da sociedade brasileira conceberam sua política externa como pragmática e coerente com a tradição histórica da diplomacia brasileira, adotando uma postura mais ativa e funcional em relação aos interesses nacionais.

Na concepção de Rubens Barbosa (2008:12) “de modo geral, a política externa do atual governo para a região não trouxe inovações, visto que todos os governos nos últimos vinte anos atribuíram grande prioridade à América do Sul e ao processo de integração regional”. Além disso, também notamos que a agenda externa para a América do Sul vem acompanhada de um projeto desenvolvimentista, multilateralista, cooperativo e nãoconfrontacionista e de consolidação do papel do Brasil de player internacional e líder regional. Tais características da diplomacia brasileira sempre estiveram presentes na história das ações exteriores brasileiras.

Seguindo esses princípios, buscando intensificar a integração regional o Brasil apresentou em 2004, durante a reunião presidencial da Amé- 
rica do Sul, em Cuzco no Peru, o projeto de criação da Comunidade SulAmericana das Nações (CASA), tendo por objetivo a formação de um espaço sul-americano integrado nos âmbitos político, social, econổmico, ambiental e de infraestrutura. Em maio de 2008, a partir das iniciativas e dos entendimentos da CASA, criou-se a União Sul-Americana das Nações2 (UNASUL). Através da criação e consolidação dessas novas instituições a diplomacia de Lula buscou fortalecer a integração regional com base no multilateralismo.

Analisaremos a seguir as iniciativas do Brasil em três pontos basilares para impulsionar a integração regional: a infraestrutura, o potencial energético e a política de segurança e defesa.

O desenvolvimento da infraestrutura regional é imprescindível para viabilizar a comunicação entre os países do bloco. Nesse sentido, Samuel Pinheiro Guimarães destaca que é parte essencial da estratégia brasileira de integração proporcionar crédito aos países vizinhos para a execução de obras de infraestrutura, e esclarece que:

Más allá de la integración de la infraestructura física en términos de carreras, puentes, ferrocarriles y de energía, es esencial la integración de las comunicaciones aéreas, por su importancia para la economía y la política, así como de los medios, en especial la televisión ,esencial para la formación del imaginario sudamericano, a través del conocimiento de la vida política, económica y social de los países de la región, hoy desconocida por el gran público y, por tanto, fuente de toda suerte de prejuicios y manipulaciones que envenenan la opinión pública y afectan los discursos, las actividades y las decisiones políticas. La TV Brasil - Canal Integración y la TELESUR son experiencias no hegemónicas de integración de las comunicaciones, así como la iniciativa brasileña de intentar establecer un padrón regional de TV Digital, con la participación de los Estados del Mercosur, inclusive en el proceso industrial (Guimaraes, 2007: 120-121).

A questão da infraestrutura física ganhou uma ênfase maior nas agendas governamentais a partir da primeira reunião de Presidentes da América do Sul em agosto de 2000, na cidade de Brasília, na qual se acordou em relação um entendimento político acerca da importância de se desenvolver uma visão regional - que incorpore e amplie as visões estritamente nacionais - na elaboração de planos de infraestrutura.

Nesta reunião, se chega a um entendimento em torno do conceito de “eixos regionais de desenvolvimento". Essa noção favorece a implementação de projetos de infraestrutura dirigidos para o desenvolvimento econômico e social sustentável das regiões envolvidas, e busca promover uma visão integrada nas áreas de energia, transportes e telecomunicações. Nesta oportunidade, os presidentes foram informados sobre o Plano de ação para a Integração da Infraestrutura Regional em América do Sul, elaborado 
pelo BIRD em coordenação com a CAF. Desse plano surge posteriormente à Iniciativa para a Integração da Infraestrutura Regional Sul-americana (IIRSA), que é uma iniciativa multinacional que envolve aos doze países da América do Sul e multisetorial, pois não somente participa o setor de transportes, como também o setor energético e fundamentalmente o setor de telecomunicações. Assim mesmo, é uma iniciativa multidisciplinária porque incluem aspectos econômicos, jurídicos, políticos, sociais, culturais e ambientais, entre outros, uma vez que contempla mecanismos de coordenação entre os governos, às instituições financeiras multilaterais que promovem e o setor privado, com o objetivo de harmonizar planos e programas de inversão com uma visão política e estratégica da região.

No conjunto dessas políticas também está a criação do Fundo para a Convergência Estrutural do Mercosul (FOCEM), cujo principal objetivo é propiciar a convergência estrutural (Programa I), o desenvolvimento da competitividade (Programa II), aprofundar a coesão social (Programa III) e fortalecer a estrutura institucional do Mercosul e o processo de integração regional (Programa IV). Dessa, com base ao princípio da solidariedade, busca-se promover a diminuição das condições de assimetrias existentes entre as diferentes regiões do bloco, garantindo que os benefícios resultantes da ampliação dos mercados sejam plenamente aproveitados por todos os Estados. Cabe ressaltar que os projetos prioritários do Fundo voltaramse para temas de interesse do Paraguai e Uruguai visando reduzir as assimetrias regionais.

A questão energética foi outro ponto em destaque. De acordo com Samuel Pinheiro Guimarães (2007), a segurança energética é central na atualidade e no futuro previsível. A integração energética e a autonomia regional em energia para garantir a segurança de abastecimento energético é prioridade absoluta da política externa brasileira para a América do Sul. Não há possibilidade de crescer $7 \%$ ao ano durante um longo período sem um abastecimento suficiente, seguro e crescente de energia. Este abastecimento depende de inversões de prazo mais ou menos longo de maturação, como prospecção de jazidas de petróleo, gás e urânio, a construção de usinas de hidro e termoelétricas, assim como nucleares.

A América do Sul, como região, tem um excedente global de energia, porém são grandes superávits atuais e potencias em certos países e com forte escassez em outros. No primeiro caso se encontram Venezuela, Equador e Bolívia para o gás e o petróleo. No caso da energia hidroelétrica, tem excedentes extraordinários no Brasil, Paraguai e Venezuela. Por outro lado, se encontram países com déficit estrutural de energia como Chile e Uruguai e casos intermediários como Peru, Colômbia e Argentina. Assim, a integração energética da região permitirá reduzir as importações extra regionais e fortalecer a economia no continente sul-americano.

Dessa forma, no esforço de fortalecer e de integrar o sistema energético da região, o Brasil tem financiado a construção de gasodutos em Argentina e se tem se empenhado na concretização do projeto do Grande 
Gasoduto do Sul que deverá vincular os maiores centros produtores de energia - Venezuela e Bolívia -, aos maiores mercados consumidores - Brasil, Argentina e Chile. Além disso, o governo brasileiro está disposto a compartir tecnologia que desenvolveu na área dos biocombustíveis, considerando que a crise de energética e ambiental somente se poderá enfrentar com eficiência a partir de uma modificação gradual da matriz energética mundial, de uma redução do consumo e dos resíduos nos países altamente desenvolvidos, principais responsáveis da emissão de gás carbônico.

Neste contexto, uma iniciativa governamental importante foi o Acordo Marco sobre Complementação Energética Regional entre os Estados parte do Mercosul e Estados Associados, firmado em 2005. O artigo $6^{\circ}$ do acordo estabelece que com o objetivo de aprofundar a integração entre as Partes, se poderão celebrar acordos regionais, sub-regionais ou bilaterais nas áreas que se anunciam a continuação, entre outras do intercâmbio comercial de hidrocarbonetos; interconexão das redes de transmissão de energia elétrica; cooperação na prospecção, exploração e industrialização dos hidrocarbonetos e fontes de energia renováveis e alternativas.

Contudo, os projetos em torno da infraestrutura e integração energética carecem de maiores recursos, além de mais vontade política para sua realização. Assim, o binômio desenvolvimento e integração passa necessariamente pela solução dos graves problemas que persistem no campo energético e de infraestrutura, apesar dos relativos avanços já conquistados nesses setores.

A defesa e segurança regional foi outro tema importante do governo Lula. Para uma melhor compreensão dessas propostas convém apresentarmos as análises de Andrew Hurrell (2007:115). Segundo o autor, o mundo pósGuerra Fria impôs uma nova significação para o conceito de segurança regional que passou a incluir questões como narcotráfico, criminalidade, migração e meio ambiente (e democracia). Consequentemente, a segurança regional passou a ser definida em termos distintos daqueles consagrados durante a polarização do sistema internacional. De um lado, passa a prevalecer à noção de segurança como "defesa coletiva da democracia", constituindo-se como mecanismo de garantia da estabilidade e a da segurança regional. De outro lado, passa-se a identificar a promoção de reformas econômicas e a integração regional como fatores catalisadores de uma ordem regional estável. O pressuposto é de que um dos resultados do processo de integração seria fazer com que os vizinhos mais vulneráveis e mais instáveis fossem sendo “envolvidos” pelas políticas integracionistas, através da elevação dos níveis de interdependência. Nesse sentido, há que se destacar o papel da integração como fator de estabilidade regional.

Neste contexto, é importante ressaltar que América do Sul e a zona andina em especial, não se constituem o que os Estados Unidos entendem como uma "ameaça" desde o ponto de vista de poder econômico, mas si como possível cenário de uma "paz mafiosa" de tendências ao caos e a desordem. O processo que tem lugar na zona dos Andes se caracteriza por 
estados instáveis (Bolívia, Equador), regimes democráticos debilitados (Venezuela) e maiores níveis de militarização (Colômbia, Equador, Peru). Às tensões interestatais (Venezuela-Colômbia, Chile-Bolívia) se somam dinâmicas de segurança transnacionais em ascensão (narcotráfico e guerrilha) e conflitos originais não somente em fatores econômicos senão também identitários.

No discurso do primeiro mandato, em 2003, o presidente Lula já identifica a América do Sul como uma alta prioridade, em especial na busca pela construção de uma região politicamente estável, próspera e unida. Nesse sentido, a região corresponde ao espaço natural de afirmação dos interesses brasileiros. Dessa forma, Amado Luiz Cervo ressalta que “(...) os objetivos traçados pelo Governo Lula são o esforço nas economias nacionais pela via de sua regionalização, a autonomia decisória na esfera política e a exclusão de intervenções externas para a solução de problemas de segurança nacional.” (Cervo, 2005:119)

Sobre esse aspecto, o chanceler Celso Amorim (2005:22) caracteriza a América do Sul como uma região com gastos militares proporcionalmente baixos, que não possui armas nucleares ou outras de destruição em massa e não participa de alianças militares incompatíveis com as políticas das Nações Unidas. O diplomata afirma que a região possui identidade própria, tornando inaplicáveis conceitos de segurança hemisférica do tipo one size fit all, difundidos pelos Estados Unidos.

Dessa forma, a região apresenta uma diferente visão sobre defesa e segurança, sobretudo o governo brasileiro, que em muitas situações inspira outros governos locais, determinando uma postura e lugar diferenciado do Brasil no cenário internacional. O objetivo de Lula foi ajustar o foco da política externa a um novo projeto de nação que fazia da inclusão social, do desenvolvimento econômico, do aprofundamento da democracia e a afirmação da soberania nacional combinada com o desejo da integração regional os eixos de um novo projeto nacional. A melhor forma de contribuir para a segurança mundial seria fazendo o seu dever de casa.

Lula apresenta a postura de seu governo quanto a problemas latentes de segurança quanto diz "não será militarmente que vamos acabar com o terrorismo, nem tampouco com o narcotráfico. Vamos acrescentar isso com muito mais densidade na hora em que a gente atacar o problema crucial que é a pobreza no mundo” (2004:73-88). Fazendo assim uma referência a clara distinção existente em seu governo entre segurança e defesa. E também às políticas adotadas pelos EUA.

É preciso destacar também que a discussão sobre a segurança na região envolve outras questões urgentes. De acordo com Samuel Pinheiro Guimarães (2006: 61-84), a América do Sul e o Brasil têm que superar quatro grandes desafios comuns a todos os países da região. O primeiro é articular as políticas que visem desconcentração de poder que reduzam as exorbitantes assimetrias sociais. O segundo consiste na superação da 
vulnerabilidade externa, através de políticas de desenvolvimento com geração e distribuição de renda, que vise privilegiar a estabilidade social no lugar da estabilidade financeira.

Um terceiro desafio se remete a transformação sustentável do enorme potencial natural da América do Sul criando vínculos de integração física e social visando aumentar a produtividade de todos os segmentos da sociedade, do estoque de capitais e dos recursos naturais. E o quarto desafio visa à transformação dos sistemas democráticos tradicionais em uma democracia efetiva, consolidada e dinamizada pela participação social, que reduza a concentração de poder em benefício da maioria. Estes foram os princípios norteadores da política externa do primeiro governo Lula e influenciou seu projeto de segurança regional.

Foi em 2003 que ministros da Defesa de doze países sul-americanos se reuniram pela primeira vez para discutir a segurança no continente e ações conjuntas a serem colocadas em prática, como a criação de uma força de paz e o combate unificado aos crimes transnacionais. Desde então propostas conjuntas de segurança regional foram abordadas em questões de desenvolvimento, integração, justiça social ou diretamente questões de defesa de um estado presente em todos os encontros e negociações mantidos pelo governo do Brasil com os países vizinhos. Dando vez a um tratado, aliança estratégica ou uma simples nota conjunta, mas o movimento para o fortalecimento da segurança regional é constante. Celso Amorim destaca que um resultado claro da atenção dada pelo governo brasileiro à região sul-americana é que a "América Latina é hoje o maior parceiro comercial do Brasil. Só a América do Sul já é maior do que os Estados Unidos e o comércio com este país está batendo recordes” (Amorin, 2006:15). Para o Ministro isso demonstra que a política externa priorizou a integração sul-americana.

\section{O Mercosul e a questão da identidade regional}

Dentro desse novo impulso a integração regional do governo Lula tornou-se fundamental transformar e aprofundar o Mercosul, criar institucionalidade de acordo com os novos objetivos. Como, por exemplo, pensar a participação do bloco em organismos multilaterais, não somente na Organização Mundial de Comércio, mas também em outros espaços, pois o comércio não é o único que é relevante. Seria positiva a projeção dessa integração regional em todos os organismos internacionais de atuação. Mas, definitivamente, a evolução da supranacionalidade é um dos principais objetivos a serem alcançados. Permitindo com isso a criação de um sentimento identitário entre os países membros.

Sobre essa questão, Luís Fernando Ayerbe (2007:132) ressalta que, nos últimos anos, acompanhando o aprofundamento dos processos de globalização e regionalização na América Latina e Caribe, tornam-se cada vez mais relevantes os estudos que buscam delimitar um espaço cultural latino-americano capaz de dar suporte aos próprios projetos de inserção. 
Fato que evidencia a importância crescente da cultura nos processos de regionalização.

Nesse sentido, o resgate dos produtos da criatividade regional isto é, seus produtos culturais expressos na literatura, música, poesia, artes plásticas e ciências -, têm como objetivo principal referendar a importância da contribuição da América Latina e Caribe para a cultura universal, ponto de apoio do seu otimismo em relação ao futuro da integração da região, pautado em fortes laços de identidade com potencial de produzir projetos que promovam o alargamento da consciência nacional de pertença.

Transpondo essas análises para o contexto específico da integração sul-americana, constata-se que o tema cultural vem ganhando importância ao lado de outras medidas políticas e econômicas para a consolidação e fortalecimento do bloco. Segundo Renato G. Flores Jr. (2007:23), assim como os países, as "Interações Regionais” precisam fortemente, em certo momento de sua evolução, de um esforço na criação de uma identidade própria. A partir da qual se torna mais importante enfatizar seus aspectos de bem público (imperfeito), ajudando o reconhecimento do processo de integração por todos os atores envolvidos ou a desenvolver. Nesse momento, o caráter público revigora, em um movimento circular, a própria identidade da integração.

Dessa forma, alguns símbolos do bloco estão sendo criados como o “projeto do passaporte comum”, contendo a estampa do Mercosul na capa, já está em curso e, futuramente, será progressivamente implantado nos países-membros. Além disso, possui também uma “bandeira”, resultante de um concurso público no âmbito de seus quatro membros. O autor ressalta que não importa se a mesma é “bonita ou adequada”, mais sim o fato que ela deve ser utilizada com maior frequência e destaque em todas as atividades, mais ou menos solenes, que representem alguma relação com o projeto de integração. Outro símbolo importante que já foi implementado em Assunção, capital do Paraguai, é o "Parlamento do Mercosul”, com eleições previstas para 2010 e $2014 .^{4}$

Merece destaque também a importância de atividades educacionais sistemáticas visando à explicação do significado (simbólico) dos fatos, de instituições, de políticas em benefícios da integração. Bons exemplos seriam os intercâmbios de estudantes universitários - de graduação e pósgraduação -, atividades que podem ter o financiamento do bloco com desvios marginais de recursos. Partindo dessa perspectiva Flores comenta:

A questão da cultura não pode ser dissociada do investimento, embora diversas discussões sobre esse último esqueçam-se do quão importante é a existência de fundos do setor cultural. Se iniciativas privadas, como a (...) Bienal de Artes Visuais, apontam para caminhos a serem explorados, esforços de integrados de promoção à cultura no contexto da integração conformariam importante ajuda desse 
trabalho. Mecanismos mútuos de dispensa de impostos, de facilitação burocrática em geral para espetáculos e promoções de um dos membros que percorram os países do bloco, de abertura de linhas de crédito para iniciativas intermembros ou ligadas à integração são algumas das diversas ações que devem ser encorajadas. (Flores, 2007:50)

Um bom exemplo de intercâmbio que tem contribuído para aproximar culturalmente os países do bloco é o diplomático. Segundo Juan Cortelletti, a cooperação das academias diplomáticas é uma das facetas mais enriquecedoras e pouco conhecidas da integração regional. Atualmente, funcionários de países sul-americanos cursam matérias no Instituto del Servicio Exterior de la Nación e representantes argentinos aprimoram sua formação conhecendo as outras academias. Através do ISEN foram firmados acordos dessa natureza com o Brasil, o mais antigo, e também com o Paraguai, Bolívia e Venezuela, e está trabalhando-se na extensão da proposta a outros países.

Em relação ao intercâmbio entre brasileiros e argentinos, os gestos de confiança são múltiplos. Comenta o exemplo de Sandra Pitta que participou em 2003 de uma viagem de estudos do Instituto Rio Branco pelo Amazonas, trajeto no qual visitam as bases militares e presenciam distintas atividades das Forças Armadas. Os funcionários argentinos foram os primeiros estrangeiros convidados a participar dessa experiência. Pitta faz o seguinte comentário de sua experiência:

Yo ya había estudiado historia brasileña, pero hacerlo en Brasil, con profesores y alumnos del país, fue una experiência muy enriquecedora (...) Además - agrega - conocer la cultura, sus raíces, la influencia africana, por ejemplo, constituye un valor agregado que facilita mucho el trabajo conjunto con diplomáticos brasileños. (Cortelletti, 2007: 162)

Assim, pelo relato da diplomata argentina, percebe-se o papel relevante da diplomacia no conhecimento e difusão da cultura e da história dos países sul-americanos que formam o bloco. Entretanto, faltam mais incentivos do Itamaraty e do Palácio San Martin para promover essas e outras formas de intercâmbio entre suas sociedades e as dos países vizinhos, pois é fundamental para construir uma consciência regional, que se constitui um elemento imprescindível para o êxito dos acordos políticos e econômicos no âmbito do Mercosul.

Como consequência da pequena importância dada à integração cultural, o patrimônio cultural dos países do bloco, pouco conhecido pelos demais, não tem sido utilizado para construir pontes entre seus povos, relações de confiança e estimular o diálogo. Na realidade, o conhecimento da cultura de seus próprios países é superficial, ao passo que, se desconhece quase que totalmente, os patrimônios histórico, material e intangível de seus vizinhos. Dessa forma: 
(...) raras são as academias que propiciam os futuros representantes no exterior uma formação cultural, suficientemente aprofundada sobre a cultura do próprio país (...) suas diferenças regionais, seu folclore e as diversas formas de religiosidade, suas indústrias culturais e os sistemas educacionais e de ciência e tecnologia. Em consequência, a imagem de seu país que ele divulgará no exterior relaciona-se, apenas, ao folclore, às belezas naturais ou algumas manifestações populares como o Carnaval ou o futebol, do Brasil; o tango, na Argentina; as Cataratas e as Missões Guaraníticas, no Paraguai, e Punta del Este, no Uruguai. (Soares, 2008: 53-69).

Nesse sentido, a diplomacia cultural se torna um fator cada vez mais relevante para uma integração de fato entre as sociedades. Segundo Mônica Leite Lessa (2002:14), a diplomacia cultural teria a função de promover ou divulgar a cultura, programas culturais, instituições culturais ou científicas, ideias ou autores de um país, sendo sua principal motivação a utilização do capital cultural do país em benefício de suas relações externas. Ela pode não ter como principal objetivo promover o país ou suas relações externas (como no caso dos intercâmbios acadêmicos), mas criar uma imagem ou marca do país. Seu grande desafio é construir imagens positivas e atraentes de países ou blocos regionais, que articulem de forma consistente e moderna seus capitais culturais e projetos de desenvolvimento e de cooperação. Edgar Telles Ribeiro (1989) destaca que o intercâmbio de pessoas; a promoção da arte e dos artistas; o ensino de língua (veículo de valores); a distribuição integrada de material de divulgação; o apoio a projetos de cooperação intelectual e técnica e a integração e a mutualidade na programação são alguns meios dos quais pode desenvolver-se uma diplomacia cultural.

De acordo com Maria Susana Arrosa Soares, as poucas políticas governamentais no sentido de promover a diplomacia cultural no bloco têm resultado em insucesso. Um bom exemplo foi um novo órgão criado, em dezembro de 2003, pelo Grupo Mercado Comum na área cultural: a Reunião Especializada de Autoridades Cinematográficas e Audiovisuais do Mercosul (RECAM). Porém, os resultados foram decepcionantes e nenhumas das iniciativas previstas atingiram seus objetivos. Soares ressalta que a maior parte dos acordos das Atas das Reuniões dos Ministros de Cultura foi implementada, porém, elas expressam mais declarações de interesses do que propostas de projetos regionais destinados a regulamentar e propiciar o intercâmbio, a circulação e a produção cultural na região.

No entanto, a Bienal do Mercosul, é um dos mais bem sucedidos projetos culturais, surgiu por iniciativa do empenho de atores privados e públicos preocupados em promover o intercâmbio de obras e de artistas latino-americanos. A Bienal realiza-se em Porto Alegre, desde 1997, por iniciativa da Fundação Bienal de Artes Visuais do Mercosul, instituição de direito privado sem fins lucrativos. O evento é financiado, sobretuḑo, por empresas (89\%), contado com recursos públicos federal, estadual e municipal. Assim, segundo seus idealizadores e realizadores, a Bienal é um 
“exercício” de integração cultural independente de governos, que ocupa a lacuna cultural deixada pelo projeto mercosuliano. Por outro lado, também releva a viabilidade de realização de projetos dessa natureza a partir da parceria entre governos, artistas, empresas, etc. Essa é uma tendência para o fomento de políticas culturais no bloco em benefício da sociedade.

Numa perspectiva comparada, durante a Era Vargas, a partir de 1933 até 1954, e ao longo do primeiro peronismo, entre 1946 a 1955, em alguns momentos, os projetos culturais contaram com o patrocínio da iniciativa privada, porém, nos dois governos o Estado atuou como um verdadeiro "mecenas" no sentido de estimular a diplomacia cultural entre os países vizinhos, visando interesses políticos e econômicos de estabelecer sua hegemonia na região (SANTOS, 2009: 355-375).

Ao também tratar sobre os símbolos mercosuliano, Miriam Gomes Saraiva (2007:65-66) destaca, entre as políticas públicas direcionadas para a integração, a importância da educação escolar, defendendo a ideia que o ensino de História e da Geografia deve incorporar a seus currículos referências a outros países do bloco de forma sistemática. Ressalta como ponto positivo o ensino do castelhano nas escolas brasileiras, e que se iniciou na década de 1980, vem apresentando resultados no sentido da construção de uma identidade do Mercosul. Contudo, acredita que deveria ser mais incentivado.

Saraiva ressalta ainda que um mecanismo de enorme importância é o incentivo financeiro e administrativo para iniciativas de caráter tanto subnacional quanto privado que colaborem para a formação desses símbolos. Nesse conjunto, a questão de difusão de intercâmbios - festivais, acesso a canais e televisão de Países-membros do bloco dentro dos marcos das TV's a cabo, facilitação de venda de produtos culturais de outros parceiros da região, difusão desses produtos em meios de comunicação nacionais -, pode ter uma contribuição muito expressiva.

Conclui ressaltando que a simbologia é um tema que deve ser definitivamente incorporado aos debates sobre o bloco, considerando ainda quando as decisões relacionadas ao grupo forem adotadas, cooperam de forma relevante na construção do Mercosul. Na opinião da autora, a extensão geográfica do bloco e a ausência da infraestrutura que permita o acesso às diferentes áreas devem ser compensadas com esforços deliberados para a conformação de uma simbologia e de uma identidade regional que possam conviver com os nacionalismos próprios desses países. Tais iniciativas, porém, repousam em vontades políticas.

\section{Considerações finais}

Concluindo, procurei apresentar as principais características da diplomacia de Lula para a América do Sul visando o revigoramento do Mercosul como estratégia de inserção internacional para superar as barreiras 
ao desenvolvimento na região e se constituir uma alternativa as imposições hegemônicas dos Estados Unidos.

Entretanto, se durante o período compreendido entre os anos de 2003 a 2007 configurou-se como um momento de revigoramento da proposta de integração sul-americana, apresentando avanços significativos, ainda existem muitos entraves políticos, econômicos e culturais que precisam ser superados para o pleno êxito do projeto mercosuliano. Dessa forma, as grandes assimetrias entre os países, as dificuldades de implantação de uma união aduaneira e de financiamento dos projetos de desenvolvimento enérgico e de infraestrutura, as divergências ideológicas adicionadas a antigas desconfianças, criam fortes obstáculos à formação de uma supranacionalidade em torno de uma identidade regional.

É importante também ressaltar que o déficit democrático do projeto de integração da América do Sul, ficando grande parte das decisões no âmbito das chancelarias e outros órgãos governamentais, dificulta a institucionalização do Mercosul. Dessa forma, a participação dos diversos setores da sociedade civil faz-se cada vez mais necessária, seja para reivindicar seus direitos, seja para contribuir na formulação da nova proposta de desenvolvimento.

Atualmente, o Mercosul encontra-se no estágio de uma união aduaneira que está negociando com a União Europeia, países dos BRIC. Também subscreveu um acordo de livre comércio com os países andinos. Entretanto, o fato de não ter possuir uma agenda de negociações com os Estados Unidos pode tornar-se um entrave considerando que Washington organizou boa parte de suas relações comerciais com a América Latina através de tratados de livre comércio. Diante desse quadro, resulta complexo compatibilizar a agressiva política externa da Venezuela, recentemente incorporada ao bloco, com a estratégia comercial externa do Mercosul. Constituiu-se assim, mas um grande desafio para as lideranças desse processo, especialmente para o Brasil. 


\section{Notas}

${ }^{1}$ Este artigo é parte da pesquisa sobre as relações entre os governos Luiz Inácio Lula da Silva e Nestor Kirchner no contexto da integração regional desenvolvida em PósDoutorado no Programa de Pós-Graduação em História Comparada do Instituto de História da UFRJ, entre os anos de 2008 a 2011. Meus agradecimentos a FAPERJ, agencia financiadora da pesquisa.

${ }^{2}$ O Brasil possui $70 \%$ do PIB da região (45\% da produção industrial), $79 \%$ da população e $72 \%$ de sua superfície. Depois vem a Argentina com 27\%, 17\% e 23\% das variáveis mencionadas. Enquanto que Uruguai e Paraguai correspondem aproximadamente 3\% do restante do Mercosul, revelando a grande desigualdade em relação de forças - estas cifras não contemplam a incorporação recente da Venezuela.

${ }^{3}$ Para maiores informações acessar http://www.pptunasur.com/inicio.php?idiom=1.

${ }^{4}$ Mesmo que não isento de problemas, o Parlamento se tiver a sua função bem explicitada, com limites bem definidos e não muito ambiciosos, pode funcionar como um poderoso instrumento para a integração, tendo fortes características de um símbolo tangível. Pressupondo assim, o exercício do voto, ato de grande valor simbólico, consubstanciando os direitos democráticos de participação e escolha. 


\section{Bibliografía}

Ayerbe, Luís Fernando (2007), “Cultura, desenvolvimento e integração na América Latina e Caribe”. Integração Latino-americana e Caribe. Fundação Memorial da América Latina: Imprensa Oficial do Estado de São Paulo, São Paulo, p. 219-251.

Amorin, Celso, Política externa do governo Lula: os dois primeiros anos. Analise da Conjuntura OPSA. Rio de Janeiro, março de 2005. Disponível em: $<$ http://observatorio.iuperj.br/artigos_resenhas/ Artigo\%20Celso\%20Amorim.pdf $>$.

Bandeira, Luiz Moniz (2009), Geopolítica e Política Exterior: Estados Unidos, Brasil e América do Sul. FUNAG, Brasília.

Bernal-Meza, Raúl (2008), “Argentina e Brasil em lá Política Internacional: regionalismo y Mercosur (estratégias, ccoperación y factores de tensión)”. Revista Brasileira de Política Internacional. 51 (2): 154-178.

Cervo, Amado Luiz (2002), "Relações internacionais do Brasil: um balanço da era Cardoso”. Revista Brasileira de Política Internacional, v. 45, n. 1, p. 5-35.

Ídem (2005), “A Política Exterior: de Cardoso a Lula”. Revista Brasileira de Política Internacional. Brasília-DF, Ano 46 n. 1, p. 129.

Cortelleti, Juan (2007), “Integración y diplomacia”. Res Diplomática (RD). Revista del Instituto del Servicio Exterior de la Nación (ISEN). Ministério de Raciones Exteriores y Culto. Segunda Época, n. 1, agosto, p. 160-165, Buenos Aires.

Fiori, José Luís (2007), “De volta ao futuro, a esquerda na América Latina”. Jornal Valor. Rio de Janeiro, 31 de janeiro.

Gonçalves, José Botafogo (2004), “Nuevo Paradigma Regional”, La Reforma, 11 de janeiro.

Ídem e Lyrio, Maurício (2003), Aliança Estratégica entre Brasil e Argentina: antecedentes, estado atual e perspectivas. CEBRI, Rio de Janeiro.

Guimarães, Samuel Pinheiro (2006), “Uma Estratégia Militar para o Brasil”. In: J.R. de Almeida Pinto, A.J. Ramalho da Rocha, R. Doring Pinho da Silva, Reflexões sobre defesa e segurança: uma estratégia para o Brasil, vol 1. Ministério da Defesa, Secretaria de Estudos e de Cooperação, 2004. p. 61-84, Brasília. Disponível em: <https://www.defesa.gov.br/enternet/sitios/ internet/ciclodedebates/>. Acesso em 13 set.

Ídem (2007) “El mundo multipolar y la integración sudamericana”. Res Diplomática $(R D)$. Revista del Instituto del Servicio Exterior de la Nación (ISEN). Ministério de Raciones Exteriores y Culto. Segunda Época, n. 1, 
agosto, p. 105-127, Buenos Aires.

Hurrel, Andrew (2007), “An emerging security community in South America?” In: Goldstein, J. e Keohane, R., Ideas And Foreign Policy: Beliefs, Institutions and Political Change. Cornell University Press, acessado em 31/07/2007, EUA.

Jagueribe, Hélio (2005), O Nacionalismo na Atualidade Brasileira. Ed. Universidade Candido Mendes, Rio de Janeiro.

Ídem (2005), Entrevista à Folha de S. Paulo. 18 de julho.

Lessa, Mônica Leite (2002), "Relações culturais internacionais”. In: Menezes, L. M., Rollenberg, D. e Filho, O M. (orgs.). Olhares sobre o político: novos ângulos, novas perspectivas. EdUERJ, Rio de Janeiro.

Rocha, A.J. Ramalho da e Silva, R. Doring Pinho da (Org.) (2004), O Brasil no Cenário Internacional de Defesa e Segurança - Pensamento Brasileiro sobre Defesa e Segurança. Ministério da Defesa, Secretaria de Estudos e de Cooperação, p.73-88, Brasília.

Meunier, Dominique (2008), “A Política Exterior de Kirchner: una mirada preliminar”. Revista Relaciones Internacionales. Publicación Semestral. Instituto de Relaciones Internacionales (IRI), deciembre 2007 - mayo. (Año 17 - n. 34), Buenos Aires.

Pereira-Bresser, Luiz Carlos (2005), “O conceito de Desenvolvimento do ISEB rediscutido”. In: Dados- Revista de Ciências Sociais. Vol. 47, n. 1, pp. 49-84, Rio de Janeiro.

Ribeiro, Edgard Telles (1989), Diplomacia Cultural: seu papel na Política Externa Brasileira. IPRI-MRE, Brasília.

Russel, Robert e Tokatlian, Juan Gabriel (2003), El Lugar de Brasil en la Política Exterior Argentina. Fondo de Cultura Económica, Buenos Aires.

Santoro, Maurício (2006), “Desenvolvimento como Integração”. In: T. Prazeres, A. Diniz e M. Santoro. O Brasil e a América do Sul: desafios no século XXI. FUNAG, Brasília.

Santos, Raquel Paz (2009), "Relações Brasil-Argentina: a cooperação cultural como elemento de integração regional”. Revista de Estudos Históricos. N. 44. Fundação Getúlio Vargas/CPDOC, p. 355-375, Rio de Janeiro.

Sennes, Ricardo e Barbosa, Alexandre de Freitas (2007), Avaliação do Potencial Econômico da Relação Brasil-Venezuela. Observatorio Político SulAmericano.

Soares, Maria Susana Arrosa (2008), “A diplomacia cultural no Mercosul”. 
Polis, Revista Latinoamericana, Volumen 13, $N^{\circ}$ 38, 2014

Revista Brasileira de Política Internacional. 51 (1): 53-69.

Vigevani, Túlio e Cepaluni, Gabriel (2007), “A Política Externa de Lula da Silva: a estratégia da autonomia pela diversificação”. Contexto Internacional. Vol. 29, n. 2, jul/dez.

Vizentini, Paulo Fagundes (2004), Relações Exteriores do Brasil (19451964): o nacionalismo e a política externa independente. Dozes, Petropolis, RJ.

Recibido: 15.09.2014

Aceptado: 20.11.2014 